V. Drozdovitch ${ }^{1}$, V. V. Yauseyenka ${ }^{2}$, V. F. Minenko ${ }^{3}$, I. V. Veyalkin ${ }^{2}$, T. S. Kukhta ${ }^{4}$, R. I. Grakovitch ${ }^{2}$, S. Trofimik ${ }^{3}$, O. N. Polyanskaya ${ }^{2, a}$, L. Starastsenka ${ }^{2}$, E.K. Cahoon ${ }^{1}$, M. Hatch ${ }^{1, b}$, M. P. Little ${ }^{1}$, A.V. Brenner ${ }^{1,5}$, E. Ostroumova ${ }^{1,6}$, K. Mabuchi' ${ }^{1}$, A.V. Rozhko ${ }^{2}$

${ }^{1}$ Division of Cancer Epidemiology and Genetics, National Cancer Institute, National Institutes of Health, 9609 Medical Center Drive, Bethesda, MD 20892-9778, USA

${ }^{2}$ Republican Research Center for Radiation Medicine and Human Ecology, 290 Ilyicha Street, Gomel, 246040, Belarus

${ }^{3}$ Institute for Nuclear Problems, Belarusian State University, 11 Bobruiskaya Street, Minsk, 220006, Belarus

${ }^{4}$ Joint Institute of Informatics Problems, National Academy of Sciences of Belarus, 6 Surhanava Street, Minsk, 220012, Belarus

${ }^{5}$ Department of Epidemiology, Radiation Effects Research Foundation, 5-2 Hijiyama Park, Minami-ku, Hiroshima City, 732-0815, Japan

${ }^{6}$ International Agency for Research on Cancer, 150 Cours Albert Thomas, 69372 Lyon CEDEX 08, France

\title{
THYROID SCREENING AND RELIABILITY OF RADIATION THYROID DOSES FOR THE BELARUSIAN IN UTERO COHORT
}

Objective. To describe the status and results of thyroid disease screening and assessment of reliability of radiation thyroid doses in the Belarusian in utero cohort of 2,965 individuals exposed to Chernobyl (Chornobyl) fallout.

Materials and methods. Thyroid screening examinations are currently underway including thyroid palpation by an endocrinologist, ultrasonographic examination by an ultrasonographer and analysis of blood samples for diagnosis of hypo- and hyperthyroidism, autoimmune thyroiditis, thyroid function tests (thyroid-stimulating hormone [TSH], thyroxine [T4], thyroid peroxidase antibody [anti-TP0], and thyroglobulin antibodies [anti-TG]). Reliability of (i) information from 780 pairs of questionnaires obtained during the first and second interviews of the mothers and (ii) thyroid doses, which were calculated for the cohort members using this information, is evaluated.

Results. As of 15 August 2021, 1,267 in utero exposed study subjects had been screened. A single thyroid nodule was diagnosed in 167 persons (13.2 \% of the total) and multiple thyroid nodules in 101 persons (8.0 \%): 189 (14.9\%) persons had nodules detected for the first time at the screening while $79(6.2 \%)$ persons had nodules detected previously (pre-screening nodules). Fifty-nine out of 268 subjects $(22.0 \%)$ with a suspicious thyroid nodule were referred to fine needle aspiration biopsy, and among them 33 (55.9\%) were biopsied. Reasonable agreement was observed for model-based doses calculated for the Belarusian in utero cohort members using data from the two interviews (Spearman's rank-correlation coefficient $r_{s}=0.74, p<0.001$ ), while measurement-based doses yielded almost perfect agreement $\left(r_{s}=0.99, p<0.001\right)$.

Conclusions. During the thyroid screening, at least one thyroid nodule was identified in 268 of 1,267 (21.2\%) in utero exposed cohort members. Seven thyroid cancer cases were identified in the cohort, including 5 pre-screening cases and 2 cases detected during the screening. Ongoing research on this unique cohort will provide important information on adverse health effects following prenatal and postnatal exposure to radioiodine and radiocesium isotopes, for which available epidemiological data are scant.

Key words: Chernobyl, Chornobyl, exposure, in utero, early life, thyroid cancer, reliability.

Problems of Radiation Medicine and Radiobiology. 2021;26:188-198. doi: 10.33145/2304-8336-2021-26-188-198

$\checkmark$ Vladimir Drozdovitch, e-mail:drozdovv@mail.nih.gov

${ }^{\mathrm{a}}$ Deceased

${ }^{\mathrm{b}}$ Retired 


\section{INTRODUCTION}

Understanding both acute and long-term health consequences of exposure to radiation is critical in developing effective countermeasures for preventing adverse health effects following radiation exposure. There is special concern regarding the health of persons exposed during vulnerable prenatal and early postnatal periods. Knowledge of the carcinogenic effects of inutero exposure to ionizing radiation derives mainly from the follow-up of the atomic bomb survivors in Hiroshima and Nagasaki [1,2] and children born to mothers exposed to diagnostic X-rays during pregnancy $[3,4]$. While these studies provide information on the effects of external acute gamma- or X-irradiation, there are also two cohorts of subjects exposed prenatally to a mixture of gamma and other types of radiation: the offspring of female workers at the Mayak plant in Russia and those born to mothers living near the Techa River [5-7]. Until recently, the most relevant sources of information on the effects of prenatal radioiodine exposure had been a cohort of 2,582 individuals in Ukraine exposed in utero to Chernobyl (Chornobyl) fallout $[8,9]$. A remarkably high excess radiationrelated risk for thyroid cancer and large thyroid nodules was reported from this study, but the risk estimates were based on a small number of cases with large statistical uncertainty.

From December 2012 through July 2017, the Republican Research Center for Radiation Medicine and Human Ecology (RRCRM\&HE, Gomel, Belarus) collaborated with the National Cancer Institute (NCI, Bethesda, MD, USA) to construct a cohort of 2,965 persons exposed in utero in Belarus. Since November 2017 the subjects of the Belarusian in utero cohort have been undergoing thyroid screening and the reliability of their radiation thyroid dose estimates has been evaluated. However, due to the COVID-19 pandemic, all study field activities involving in-person interaction have been suspended since April 2020, although thyroid screening and re-interview of the mothers on a smaller scale were resumed in August 2020. This paper reports the study progress as of August 15, 2021.

\section{OBJECTIVES}

The objectives of this paper are: (1) to describe the medical screening in progress in the Belarusian in utero cohort of individuals exposed to ${ }^{131} \mathrm{I}$, focused on thyroid cancer and other thyroid diseases, including follicular adenoma, benign nodules, diffuse goiter, hypothyroidism, hyperthyroidism, and autoimmune thyroiditis, and (2) to report on the assessment of the reliability of radiation doses for the cohort members using repeated personal dosimetry interviews of their mothers.

\section{MATERIALS AND METHODS \\ Study population}

The Belarusian in utero cohort consists of 2,965 childmother pairs, including 26 pairs of twins, born to 2,939 mothers. The children (referred to here as 'subjects') were born between 26 April 1986 and 31 March 1987 so that their mothers were pregnant at some point between 26 April 1986 and 30 June 1986 - the twomonth period in which significant ${ }^{131} \mathrm{I}$ exposure occurred after the Chernobyl accident. At the time of the accident (ATA), mothers of most cohort members ( $\mathrm{n}=2,553,86.1 \%$ of the total) lived in Gomel Oblast, while mothers of $290(9.8 \%)$ and $31(1.0 \%)$ subjects lived in Mogilev and Minsk Oblast, respectively (Fig. 1). Mothers of 91 individuals (3.1\%) resided outside the study area ATA but had moved into the study area shortly after the accident but before 30 June 1986 . For more than $70 \%$ of the study subjects $(n=2,089)$, mothers lived in raions most heavily contaminated from Chernobyl fallout (as shown in filled circles, Fig. 1).

\section{Thyroid screening of the Belarusian in utero cohort}

Because of significant radiation exposure to the thyroid gland from ${ }^{131} \mathrm{I}$, medical screening focuses on thyroid cancer and other thyroid diseases, including follicular adenoma, benign nodules, diffuse goiter, hypothyroidism, hyperthyroidism, and autoimmune thyroiditis. Thyroid screening examinations have been performed at the RRCRM\&HE since November 2017 in accordance with a modified version of the standardized thyroid screening procedures used in the earlier thyroid screening study of the NCI-supported Belarusian-American cohort of subjects exposed to ${ }^{131} \mathrm{I}$ in childhood and adolescence (BelAm cohort) [10]. Standardized thyroid screening examinations include thyroid palpation by an endocrinologist and ultrasonographic (US) examination by a trained ultrasonographer. Based on palpation and US findings, a patient could be referred for fine needle aspiration biopsy, and then if indicated, for surgical treatment and histopathological diagnosis. Blood samples are collected for diagnosis of thyroid disorders (e.g., functional thyroid diseases, autoimmune thyroiditis) and medical followup. In addition, whole blood samples $(10 \mathrm{~mL})$ from study subjects are frozen for future molecular studies. 


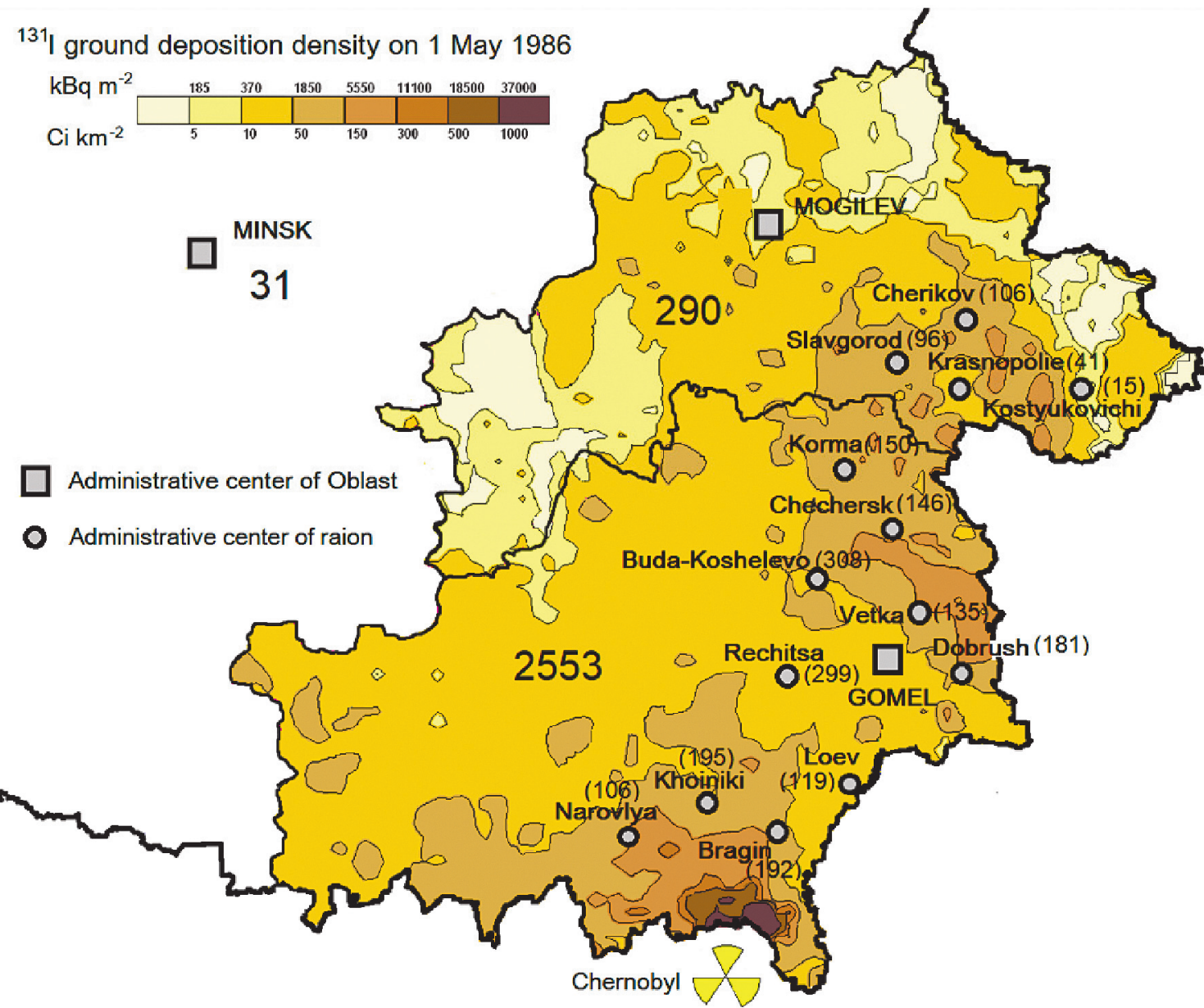

Figure 1. Geographical distribution of the Belarusian in utero cohort members according to their mothers' residence at the time of the Chernobyl accident and ${ }^{131} \mathrm{I}$ deposition density.

Mothers of 91 cohort members, who resided outside the study area, are not shown. Administrative centers of raions most heavily contaminated from the fallout are shown with filled circles, number of cohort members in the raion is given in parentheses.

\section{Thyroid doses for the cohort members Calculation of thyroid doses}

Individual thyroid doses were reconstructed for each cohort member for the following pathways of exposure: (1) prenatal ${ }^{131}$ I intake by the mother and postnatal ${ }^{131} \mathrm{I}$ intake by the infant from breast milk and/ or other foodstuffs, if the cohort member was born between 26 April and 30 June 1986; (2) prenatal and postnatal (until 5 years of age) external irradiation from gamma-emitting radionuclides deposited on the ground; and (3) prenatal irradiation from the mother's consumption of foodstuffs contaminated with ${ }^{134} \mathrm{Cs}$ and ${ }^{137} \mathrm{Cs}$ and postnatal irradiation (until 5 years old) from the child's consumption of foodstuffs contaminated with ${ }^{134} \mathrm{Cs}$ and ${ }^{137} \mathrm{Cs}$.

Information required for estimation of individual prenatal and postnatal thyroid doses for the cohort subjects was collected during personal interviews of their mothers conducted between 19 December 2012 and 22 July 2017. The study questionnaire included questions on: pregnancy and term of delivery; mother's and subject's residential history between 26 April 1986 and 31 March 1992; mother's consumption rates and dates of milk from privately owned cows or goats, milk from a commercial trade network, milk products and leafy vegetables between 26 April and 30 June 1986; dates of breastfeeding; mother's consumption rates and dates of consumption of locally produced foodstuffs after 30 June 1986 during pregnancy and/or breastfeeding; and subject's consumption rates of locally produced foodstuffs at age $0-1,1-2$, and $2-5$ years old.

Prenatal thyroid doses were estimated using input data specific to the cohort member's mother (personal interview and direct thyroid measurement, when available), and ecological data $\left({ }^{131} \mathrm{I}\right.$ ground deposition in the settlements). Ecological and biokinetic models were used to calculate mother's «model-based» thyroid dose due to ${ }^{131}$ I intake with contaminated air and foodstuffs, accounting for individual behavior and con- 
sumption reported during the personal interview. The model-based thyroid dose for the mother served as the basis for calculating model-based thyroid dose to the fetus's thyroid gland using the model from the ICRP Publication 88 [11]. There were 656 subjects born between 26 April and 30 June 1986 who were exposed to ${ }^{131} \mathrm{I}$ postnatally. Their thyroid doses were estimated considering child's breastfeeding and consumption of locally produced foodstuffs.

Individual radiation measurement data for ${ }^{131} I$ thyroidal activity were used to calibrate model-based dose and to estimate the most reliable «measurement-based» thyroid doses due to ${ }^{131} \mathrm{I}$ intake. The following three scenarios were utilized to characterize 2,939 mothers of cohort members in relation to the direct thyroid measurements:

1. Direct thyroid measurements were made in AprilJune 1986 with 286 mothers (9.7\%), including 3 mothers with twins.

2. Direct thyroid measurements were not made in study subject's mother but were made in other 10,430 women of child-bearing age residing in the same settlement or raion. This category included 2,088 women (71.1\%).

3. Mothers of the cohort members residing in areas where direct thyroid measurements were not conducted. This category included 565 mothers (19.2\%).

A detailed description of methodology and results of the thyroid dose calculation for the Belarusian in utero cohort can be found elsewhere [12].

\section{Evaluation of reliability of dose reconstruction}

There are uncertainties in the information collected by personal interviews of mothers regarding residential history and individual diet approximately 30 years after the Chernobyl accident. Our previous study among 11,732 persons from the Belarusian-American cohort, who were exposed in childhood [13], showed that if dose-related measurements are unavailable for the study subjects and only modeling is used for dose calculation, high quality individual behavior and dietary data for the study subjects are required to provide realistic and reliable dose estimates. As the direct thyroid measurement data were available only for about $10 \%$ of mothers of the Belarusian in utero cohort members, evaluation of uncertainty in thyroid doses due to possibly poor memory recall is especially important in this cohort.

Since the beginning of 2018, a special study has been conducted to re-interview a sample of 1,406 mothers using the same study questionnaire as was used for the first interview conducted between 2012 and 2017. Information collected from the second personal interviews is being used to estimate thyroid doses to the study subjects and to compare these new estimates with the estimates calculated based on the information from the first interview.

\section{Statistical analysis}

The percentage of agreement, the nonparametric Spearman's rank-correlation coefficient $\left(r_{s}\right)$ and the kappa statistics $(\kappa)$ were used to measure the degree of agreement of the responses between the two interviews. For the responses with text, i.e., name of settlement, the percentage of agreement between the answers was estimated. Numerical responses were treated in two ways: (a) for whole numbers, i.e., number of settlements of residence, the percentage of agreement and Spearman's rank-correlation coefficients were calculated; and (b) for consumption rates and thyroid dose estimates, i.e., values that could not be expected to be exactly the same, the data were categorized in intervals, and the percentage of agreement in the categories were estimated. Kappa-statistics ( $\kappa)$ and Spearman's rank-correlation coefficients $\left(r_{s}\right)$ were used only for pairs without missing responses, such as «I do not remember». Kappa statistics $\kappa<0$ indicates no agreement, while $0-0.20$ range corresponds to a slight agreement, $0.21-0.40$ to fair, $0.41-0.60$ to moderate, $0.61-0.80$ to substantial, and $0.81-1.0$ almost perfect agreement [14]. The two sets of consumption rates and thyroid doses were also compared using the Wilcoxon test, because values were not normally distributed; here, the $p_{w}$-value represents the significance level of whether data sets differ.

\section{RESULTS AND DISCUSSION}

\section{Thyroid screening of the Belarusian in utero cohort}

Between November 2017 and August 2021, 1,901 $(64.1 \%)$ of the 2,965 cohort members were contacted and invited for thyroid screening examination. Of these, 1,705 agreed to screening, of whom 1,267 (74.3\%) were examined and $242(14.2 \%)$ were scheduled for the screening; 105 persons $(6.2 \%)$ did not participate in the study because of death, serious physical disability, or migration, while 91 (5.3\%) refused to participate because of life events, pregnancy, etc.

Overall, at least one thyroid nodule was diagnosed in $268(21.2 \%)$ of the 1,267 Belarusian in utero cohort members. Of these, more than two-thirds (189 persons) had a nodule detected during the current screen- 
Table 1

Thyroid nodule pathology detected pre-screening and during the screening of the Belarusian in utero cohort

\begin{tabular}{|c|c|c|c|c|c|c|}
\hline \multirow[t]{2}{*}{ Diagnosis } & \multicolumn{2}{|c|}{ Pre-screening } & \multicolumn{2}{|c|}{ Detected during the screening } & \multicolumn{2}{|c|}{ Total } \\
\hline & $\mathbf{N}$ & $\%^{a}$ & $\mathbf{N}$ & $\%$ & $\mathbf{N}$ & $\%$ \\
\hline $\begin{array}{l}\text { Solitary thyroid nodule }(\mathrm{mm}): \\
<5 \\
5-10 \\
>10\end{array}$ & $\begin{array}{c}39 \\
3 \\
22 \\
14\end{array}$ & $\begin{array}{l}3.1 \\
0.2 \\
1.7 \\
1.1\end{array}$ & $\begin{array}{c}128 \\
71 \\
50 \\
7\end{array}$ & $\begin{array}{c}10.1 \\
5.6 \\
3.9 \\
0.6\end{array}$ & $\begin{array}{c}167 \\
74 \\
72 \\
21\end{array}$ & $\begin{array}{c}13.2 \\
5.8 \\
5.7 \\
1.7\end{array}$ \\
\hline $\begin{array}{l}\text { Multiple thyroid nodules (mm): } \\
<5^{b} \\
5-10 \\
>10\end{array}$ & $\begin{array}{c}40 \\
5 \\
14 \\
21\end{array}$ & $\begin{array}{l}3.2 \\
0.4 \\
1.1 \\
1.7\end{array}$ & $\begin{array}{l}61 \\
23 \\
27 \\
11\end{array}$ & $\begin{array}{l}4.8 \\
1.8 \\
2.1 \\
0.9\end{array}$ & $\begin{array}{c}101 \\
28 \\
41 \\
32\end{array}$ & $\begin{array}{l}8.0 \\
2.2 \\
3.2 \\
2.5\end{array}$ \\
\hline Total & 79 & 6.2 & 189 & 14.9 & 268 & 21.2 \\
\hline
\end{tabular}

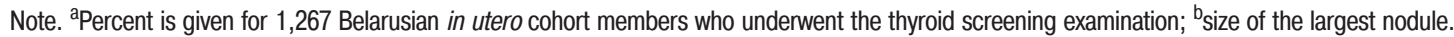

ing while 79 persons had a nodule found prior to the screening (pre-screening) (Table 1). The prevalence of screening-detected nodules of $14.9 \%$ in this Belarusian cohort is slightly higher than that of $13.5 \%$ observed in the Ukrainian in utero cohort during the second-cycle thyroid screening in 2012-2015 [9]. Of the 268 persons with nodules, $167(62.3 \%)$ had a solitary nodule, while $101(37.7 \%)$ had multiple nodules. Nodules detected during the screening were more frequently solitary than multiple, while pre-screening cases were evenly distributed with respect to single vs. multiple nodularity. In addition, nodules tended to be smaller in those detected during the screening than in pre-screening cases.

Fifty-nine out of 268 subjects $(22.0 \%)$ with thyroid nodule were referred to fine needle aspiration biopsy, and among them 34 (57.6\%) were biopsied. Two persons underwent surgery: one for thyroid cancer and one for nodular goiter. To date, 7 thyroid cancers have been identified in the cohort, including 5 pre-screening cases, which were reported prior to screening or through linkage to the Belarusian National Cancer Registry, and 2 cases detected during the screening. It should be noted that the two screening cycles of the Ukrainian in utero cohort identified 8 thyroid cancers [9].

For detection of functional thyroid disorders (e.g., hypo- and hyperthyroidism, autoimmune thyroiditis), thyroid function tests (thyroid-stimulating hormone $[\mathrm{TSH}]$, thyroxine $\left[\mathrm{T}_{4}\right]$, thyroid peroxidase antibody [anti-TPO], and thyroglobulin antibodies [anti-TG]) were performed for 1,203 (94.9\%) screened individuals.

\section{Thyroid doses for cohort members}

Table 2 shows the total (prenatal and postnatal) thyroid doses from ${ }^{131} \mathrm{I}$ intake, external exposure and ingestion of radiocesium isotopes. The mean thyroid dose from all exposure pathways in the cohort was $137 \mathrm{mGy}$, including $130 \mathrm{mGy}$ from ${ }^{131} \mathrm{I}$ intake, $4.9 \mathrm{mGy}$ due to external irradiation, and $2.5 \mathrm{mGy}$ due to ingestion of cesium isotopes. The thyroid doses from ${ }^{131} \mathrm{I}$ intake ranged up to $14.8 \mathrm{~Gy}$, from external irradiation - up to $102 \mathrm{mGy}$, while doses due to ingestion of radiocesium isotopes did not exceed $47 \mathrm{mGy}$.

The mean prenatal thyroid dose due to ${ }^{131} \mathrm{I}$ intake in the Belarusian in utero cohort (123 mGy) was higher than that of $73 \mathrm{mGy}$ for the Ukrainian in utero cohort

Table 2

Thyroid doses from different exposure pathways estimated for the Belarusian in utero cohort subjects [12]

\begin{tabular}{|c|c|c|c|c|c|}
\hline \multirow{2}{*}{$\begin{array}{l}131 \text { I thyroid dose } \\
\text { categorya (mGy) }\end{array}$} & \multirow{2}{*}{$\mathbf{N}$} & \multicolumn{3}{|c|}{ Mean thyroid dosea (mGy) due to } & \multirow{2}{*}{$\begin{array}{l}\text { Mean total thyroid } \\
\text { dosea (mGy) }\end{array}$} \\
\hline & & Intake of ${ }^{131}$ I & External exposure & ${ }^{134,137} \mathrm{Cs}$ ingestion & \\
\hline 0 & 338 & 0 & 4.0 & 2.3 & 6.3 \\
\hline $0.001-19.9$ & 1,218 & 4.8 & 4.3 & 2.5 & 12 \\
\hline $20-49.9$ & 392 & 33 & 4.5 & 2.2 & 39 \\
\hline $50-99.9$ & 292 & 73 & 4.4 & 2.1 & 79 \\
\hline $100-199.9$ & 272 & 142 & 4.6 & 2.2 & 149 \\
\hline $200-499.9$ & 290 & 304 & 6.4 & 2.8 & 313 \\
\hline $500-999.9$ & 108 & 682 & 9.5 & 3.6 & 695 \\
\hline$\geq 1000$ & 55 & 2,620 & 12 & 2.7 & 2,640 \\
\hline Entire cohort & 2,965 & 130 & 4.9 & 2.5 & 137 \\
\hline
\end{tabular}

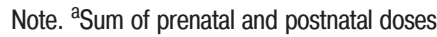


[15]. This could be expected as recruitment of the Belarusian in utero cohort members was focused on the most contaminated regions [16], while around $40 \%$ of the Ukrainian in utero cohort included individuals from low contaminated regions in Ukraine [8].

\section{Evaluation of reliability of doses reconstructed for the in utero cohort}

One-thousand and fifty $(1,050$, or $74.7 \%)$ of the 1,406 mothers of the cohort subjects were contacted and invited for a second dosimetric interview. Of these, 988 $(94.1 \%)$ agreed to the interview, of whom $780(79.0 \%)$ were interviewed and 146 (14.8\%) were scheduled for the interview. Thirty-six mothers $(3.6 \%)$ were excluded from the study because of death, serious physical disability, or migration; 26 (2.6\%) refused to participate because of life events, etc.

Information from 780 pairs of questionnaires obtained during the first and second personal interviews of the mothers has been analyzed for consistency of respondents' answers. Table 3 shows consistency of the answers on questions about consumption rates of cow's milk, milk products, and leafy vegetables that are the most important information for calculation of thyroid doses due to ${ }^{131}$ I intake.

Table 4 provides the prenatal, postnatal, and total thyroid doses from ${ }^{131} \mathrm{I}$ for the cohort members calculated using individual behavior and consumption data reported by 780 mothers during the two interviews. As noted above, two types of thyroid doses were calculated for cohort members: (i) using an ecological model, the socalled model-based dose; and (ii) the so-called measurement-based dose, which was obtained by adjusting the model-based dose for ${ }^{131} \mathrm{I}$ thyroid activity measured in cohort member's mother [12]. A reasonable agreement was observed $\left(r_{s}=0.74, p<0.001\right)$ for total (prenatal and postnatal) model-based doses calculated using data from the two interviews, while measurement-based doses calculated using data from the two interviews yielded the better agreement $\left(r_{s}=0.99, p<0.001\right)$.

Figure 2 compares the prenatal model-based thyroid doses due to ${ }^{131} \mathrm{I}$ calculated for the members of Belarusian in utero cohort using information from the first and second interviews. The model-based thyroid doses estimated for the same cohort member using the results of different interviews were spread over four orders of magnitude. For $72 \%$ of the model-based thyroid doses the two sets of doses agreed within a factor of 3, while for $11 \%$ of the cohort members a difference in the model-based doses was less than $10 \%$. The mean ratio of individual model-based doses calculated using data from the second interview to dose calculated using data of the first interview was $2.0 \pm 4.7$, and the median of ratios was 0.95 .

Better agreement was observed for the prenatal measurement-based doses calculated for 105 individuals whose mothers have direct thyroid measurements (Figure 3). For $93 \%$ of the measurement-based doses the two sets of doses agreed within a factor of 3 . A difference of less than $10 \%$ in the measurement-based

\section{Table 3}

Consistency of the answers provided by 780 mothers of the Belarusian in utero cohort members during two personal interviews

\begin{tabular}{|c|c|c|c|c|c|c|c|}
\hline \multirow{2}{*}{ Parameter } & \multicolumn{2}{|r|}{ First interview } & \multicolumn{2}{|r|}{ Second interview } & \multirow{2}{*}{$p_{w}-$ value $^{\mathrm{a}}$} & \multirow{2}{*}{$r_{s}^{b}$} & \multirow{2}{*}{$\begin{array}{c}\text { Agreed }^{c} \\
(\%)\end{array}$} \\
\hline & $\mathbf{N}$ & Consumption rate $\left(\mathrm{L}(\mathrm{g}) \mathrm{d}^{-1}\right)$ & $\mathbf{N}$ & Consumption rate $\left(\mathrm{L}(\mathrm{g}) \mathrm{d}^{-1}\right)$ & & & \\
\hline \multicolumn{8}{|c|}{ Consumption of privately owned cow's milk ${ }^{d}$} \\
\hline Mean $\pm S D^{e}$ & 400 & $0.54 \pm 0.52$ & 407 & $0.47 \pm 0.45$ & 0.001 & 0.55 & 61 \\
\hline Median & & 0.50 & & 0.30 & & $p<0.001$ & \\
\hline Range & & $0.005-3.0$ & & $0.005-3.0$ & & & \\
\hline \multicolumn{8}{|c|}{ Mean consumption of cow's milk from a commercial trade network ${ }^{\mathrm{d}}$} \\
\hline Mean \pm SD & 285 & $0.27 \pm 0.24$ & 303 & $0.24 \pm 0.28$ & 0.054 & 0.41 & 60 \\
\hline Median & & 0.21 & & 0.13 & & $p<0.001$ & \\
\hline Range & & $0.01-1.1$ & & $0.003-2.0$ & & & \\
\hline \multicolumn{8}{|l|}{ Milk products } \\
\hline Mean \pm SD & 662 & $0.17 \pm 0.13$ & 653 & $0.18 \pm 0.12$ & 0.013 & & 51 \\
\hline Median & & 0.19 & & 0.20 & & $p<0.001$ & \\
\hline Range & & $0.04-1.0$ & & $0.002-1.0$ & & & \\
\hline \multicolumn{8}{|l|}{ Leafy vegetables } \\
\hline Mean \pm SD & 565 & $0.044 \pm 0.039$ & 585 & $0.038 \pm 0.040$ & $<0.001$ & & 34 \\
\hline Median & & 0.025 & & 0.025 & & $p<0.001$ & \\
\hline Range & & $0.001-0.3$ & & $0.001-0.3$ & & & \\
\hline
\end{tabular}

Notes. ${ }^{a} p_{w}$-value represents the significance level of whether the individual valuesof consumption ratesdiffer according to Wilcoxon test; ${ }^{\circ}$ Spearman's rank-correlation coefficient and $p$-value for the individual values of consumption rates; ${ }^{c}$ percent of agreement between two questionnaires for the categories of consumption rates; ${ }^{d}$ arithmetic mean of consumption rates between 26 April and 10 May 1986; 'SD, the standard deviation. 


\section{ЕПІДЕМІОЛОГІЯ ТА ДОЗИМЕТРІЯ}

\section{Table 4}

Prenatal, postnatal and total thyroid doses (mGy) for the cohort members from ${ }^{131} \mathrm{I}$ calculated using individual behavior and consumption data reported by 780 mothers during the two interviews

\begin{tabular}{|c|c|c|c|c|c|c|}
\hline \multirow[t]{2}{*}{ Parameter } & \multirow[t]{2}{*}{$\mathbf{N}^{\mathrm{a}}$} & \multicolumn{2}{|c|}{$\begin{array}{c}\text { Thyroid doses due to }{ }^{131} I \text { intake (mGy) calculated } \\
\text { using data reported during }\end{array}$} & \multirow[t]{2}{*}{$p_{w}$-value ${ }^{a}$} & \multirow[t]{2}{*}{$r_{s}^{b}$} & \multirow{2}{*}{$\begin{array}{l}\text { Agreed }^{c} \\
(\%)\end{array}$} \\
\hline & & First interview & Second interview & & & \\
\hline $\begin{array}{l}\text { Prenatal model- } \\
\quad \text { Mean } \pm \mathrm{SD}^{\mathrm{e}} \\
\text { Median } \\
\text { Range }\end{array}$ & 606 & $\begin{array}{c}179 \pm 334 \\
101 \\
0.002-5,580\end{array}$ & $\begin{array}{c}174 \pm 476 \\
72.9 \\
0.002-10,570\end{array}$ & 0.004 & $\begin{array}{c}0.79 \\
p<0.001\end{array}$ & 47 \\
\hline $\begin{array}{l}\text { Postnatal mode } \\
\text { Mean } \pm \text { SD } \\
\text { Median } \\
\text { Range }\end{array}$ & 198 & $\begin{array}{c}26 \pm 65 \\
2.4 \\
0.002-584\end{array}$ & $\begin{array}{c}29 \pm 66 \\
2.5 \\
0.002-584\end{array}$ & 0.825 & $\begin{array}{c}0.84 \\
p<0.001\end{array}$ & 61 \\
\hline $\begin{array}{l}\text { Total model-bas } \\
\text { Mean } \pm \text { SD } \\
\text { Median } \\
\text { Range }\end{array}$ & 765 & $\begin{array}{c}183 \pm 330 \\
110 \\
0.002-5,580\end{array}$ & $\begin{array}{c}180 \pm 470 \\
85 \\
0.002-10,570\end{array}$ & 0.007 & $\begin{array}{c}0.74 \\
p<0.001\end{array}$ & 47 \\
\hline $\begin{array}{l}\text { Prenatal measu } \\
\text { Mean } \pm \text { SD } \\
\text { Median } \\
\text { Range }\end{array}$ & $\begin{array}{l}\text { d dose } \\
105\end{array}$ & $\begin{array}{c}644 \pm 1,760 \\
88 \\
0.001-14,750\end{array}$ & $\begin{array}{c}642 \pm 1,940 \\
88 \\
0.003-17,500\end{array}$ & 0.136 & $\begin{array}{c}0.99 \\
p<0.001\end{array}$ & 84 \\
\hline $\begin{array}{l}\text { Postnatal meas } \\
\text { Mean } \pm \text { SD } \\
\text { Median } \\
\text { Range }\end{array}$ & $\begin{array}{c}e d \text { dost } \\
18\end{array}$ & $\begin{array}{c}175 \pm 451 \\
1.4 \\
0.006-2,040\end{array}$ & $\begin{array}{c}461 \pm 701 \\
6.7 \\
0.002-7,740\end{array}$ & 0.231 & $\begin{array}{c}0.95 \\
p<0.001\end{array}$ & 42 \\
\hline $\begin{array}{l}\text { Total measurem } \\
\text { Mean } \pm \text { SD } \\
\text { Median } \\
\text { Range }\end{array}$ & $\begin{array}{l}\text { lose } \\
105\end{array}$ & $\begin{array}{c}678 \pm 1,760 \\
99 \\
0.001-14,750\end{array}$ & $\begin{array}{c}729 \pm 2,050 \\
98 \\
0.003-17,500\end{array}$ & 0.286 & $\begin{array}{c}0.99 \\
p<0.001\end{array}$ & 83 \\
\hline
\end{tabular}

Notes. ${ }^{2}$ Number of cohort members with non-zero prenatal and postnatal doses calculated using two interviews; ${ }^{b} p_{w}$ value represents the significance level of whether the individual dose-values differ according to Wilcoxon test; 'Spearman's rank-correlation coefficient and $p$-value for the individual dose-values; ${ }^{\mathrm{d}}$ percent of agreement between two categories of dose-values, excluding zero prenatal and postnatal doses; ${ }^{\text {eSD }}$, the standard deviation.

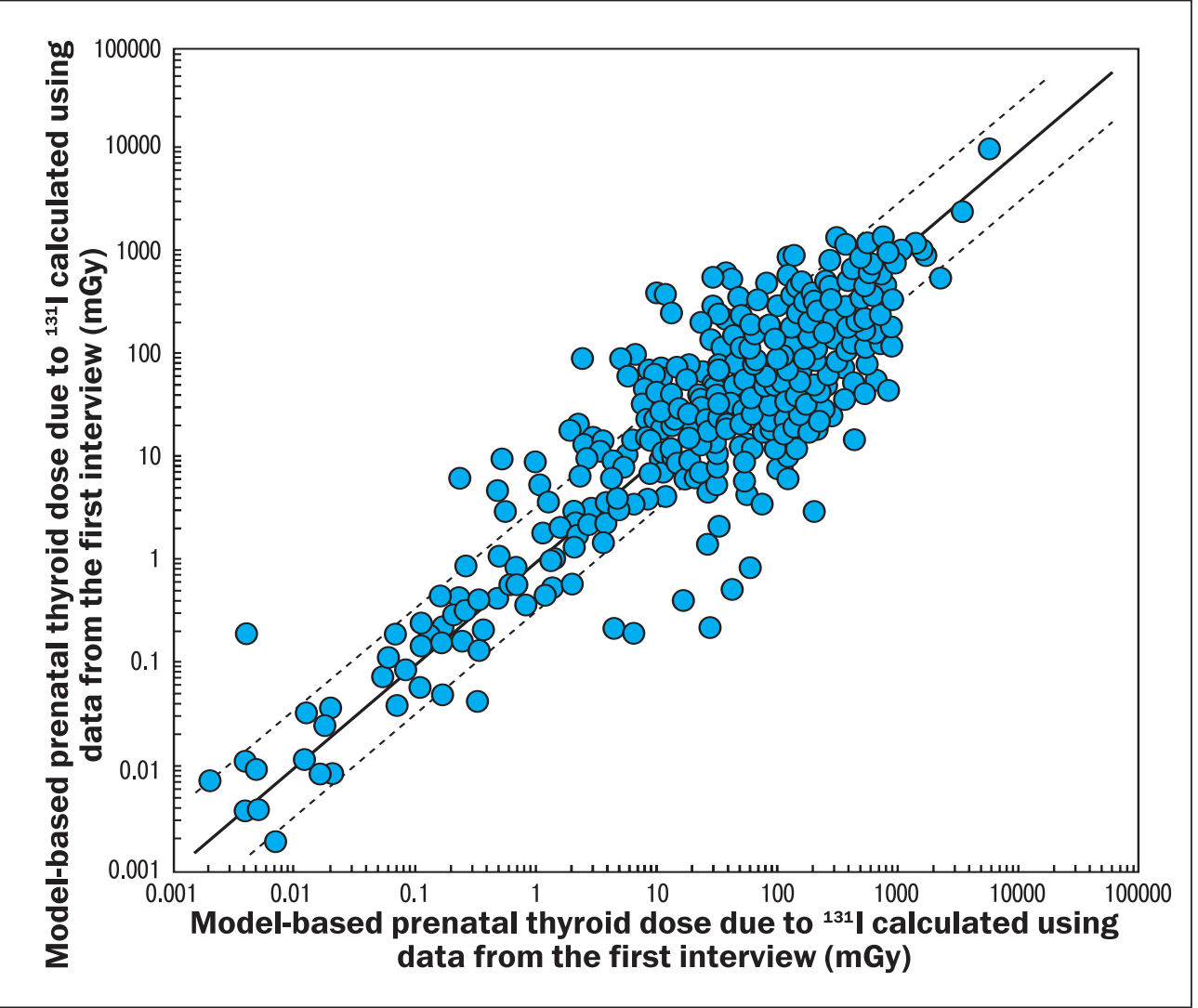

Figure 2. Comparison of model-based prenatal thyroid doses due to ${ }^{131} \mathrm{I}$ calculated using information from the first and second interviews.

Dashed lines show factor of 3 difference between two sets of doses. 


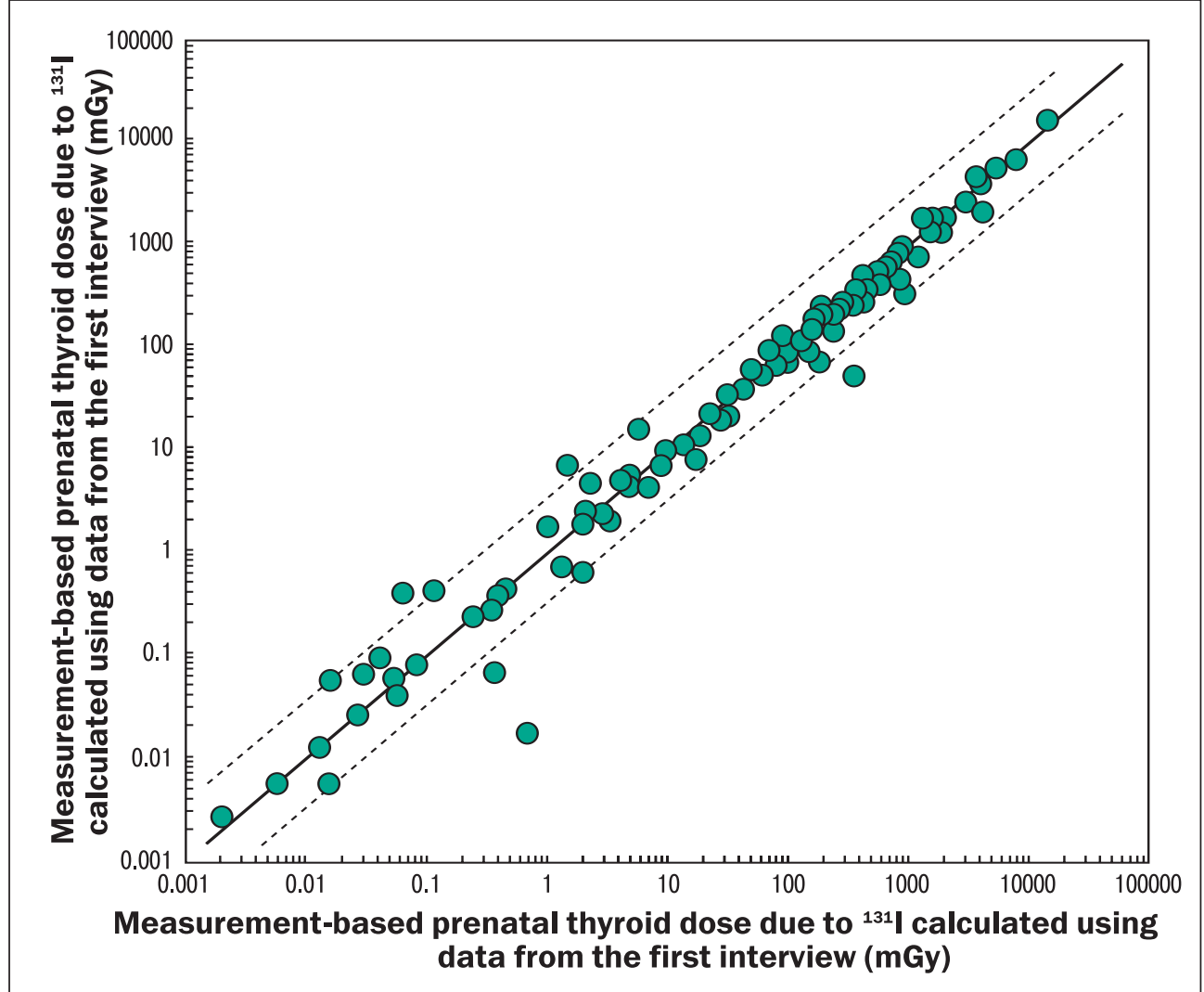

Figure 3. Comparison of measurement-based prenatal thyroid doses due to ${ }^{131}$ I calculated using information from the first and second interviews.

Dashed lines show factor of 3 difference between two sets of doses. doses calculated using data collected from two interviews was found for $51 \%$ of cohort members. The mean ratio of the measurement-based doses calculated using data from the second interview to doses calculated using data from the first interview was $1.1 \pm 0.9$, and the median of ratios was 1.0. This confirmed the previous observation that if measurements of ${ }^{131} \mathrm{I}$ thyroid activity were available for an individual, the quality of questionnaire data, in general, did not influence the precision of dose estimates [13]. However, there are 5 cohort members for whom the difference between two measurement-based doses exceeded 3 times (Fig. 3). The most likely reasons for this difference are (i) unreliable answers on residential history provided during the personal interviews or (ii) a thyroid measurement was mistakenly assigned to the mother of a cohort member [17].

Pregnancy and childbirth at the time of the Chernobyl nuclear reactor accident was a unique event for mothers of the study subjects. The statistics on agreement, i.e., percent agreed and kappa statistics ( $\kappa)$, obtained in this study were compared with those in the BelarusianAmerican cohort of individuals exposed in childhood [13]. Table 5 shows the consistency of answers between two personal interviews of 780 mothers of the

\section{Table 5}

Thyroid doses from different exposure pathways estimated for the Belarusian in utero cohort subjects [12]

\begin{tabular}{|c|c|c|c|c|}
\hline \multirow{2}{*}{ Characteristics } & \multicolumn{2}{|c|}{ In utero cohort } & \multicolumn{2}{|c|}{ BelAm cohort [13] } \\
\hline & Agreed $^{\mathrm{a}}(\%)$ & $\kappa^{b}\left(\right.$ or $\left.r_{s}^{c}\right)$ & Agreed ( \%) & $\kappa\left(\right.$ or $\left.r_{s}\right)$ \\
\hline \multicolumn{5}{|l|}{ Residential history } \\
\hline Name of settlement ATA & 90 & - & 88 & - \\
\hline Date of first relocation & 57 & 0.720 & 42 & 0.329 \\
\hline Name of settlement of first relocation & 71 & - & 49 & - \\
\hline \multicolumn{5}{|l|}{ Consumptions of foodstuffs } \\
\hline Source of cow's milk & 57 & 0.357 & 56 & 0.381 \\
\hline Consumption of cow's milk & 63 & 0.327 & 54 & 0.334 \\
\hline Consumption of milk products & 50 & 0.127 & 34 & 0.099 \\
\hline Stable iodine administration (Yes / No) & 88 & 0.522 & 75 & 0.487 \\
\hline \multicolumn{5}{|l|}{ Thyroid dose from ${ }^{131} /$ intake } \\
\hline Model-based thyroid dose & $47^{d}$ & $0.79^{d}$ & 51 & 0.66 \\
\hline Measurement-based thyroid dose & $84^{\mathrm{d}}$ & $0.99^{d}$ & 96 & 0.97 \\
\hline
\end{tabular}

Notes. ${ }^{a}$ Percent of agreement between two questionnaires or dose-values; 'bappa statistics; 'Spearman's rank-correlation coefficient; dprenatal thyroid dose. 
Belarusian in utero cohort members and 2,664 pairs of questionnaires for the 1,994 mothers of the subjects in the Belarusian-American cohort (some on the mothers in this cohort were interviewed more than once). Responses from two personal interviews of mothers were found to be more consistent among mothers of the Belarusian in utero cohort members than among mothers of the Belarusian-American cohort members. This confirms an earlier study reporting that memory recall can be more accurate if a woman is asked about unique events in her life, like pregnancy [18].

\section{CONCLUSIONS}

The Belarusian in utero cohort provides a rare opportunity for elucidating effects of radiation exposure during the gestation period on thyroid cancer and other health outcomes. Standardized thyroid screening examination of the Belarusian in utero cohort, includes thyroid palpation by an endocrinologist and ultrasonographic (US) examination by a trained ultrasonographer as well as diagnostic tests for functional thyroid disorders ( $\mathrm{TSH}, \mathrm{T}_{4}$, anti-TPO, and anti-TG), including hypo- and hyper-thyroidism and autoimmune thyroiditis.

A special dosimetry study is in progress to evaluate the reliability of dose estimates for the in utero cohort members. For this purpose, repeated interviews of 780 mothers of the cohort members have been conducted to date. Information collected from the second round of personal interviews was used to estimate de novo thyroid doses to the study subjects and to compare these estimates with the estimates calculated based on the information from the first round of interviews. It was found that consistency of answers between two personal interviews is better among mothers of the Belarusian in utero cohort members than that among mothers of the Belarusian-American cohort members.

Lifelong health consequences of exposure to ionising radiation in utero are of special concern after acciden-

\section{REFERENCES}

1. Preston DL, Cullings H, Suyama A, Funamoto S, Nishi N, Soda M, Mabuchi K, Kodama K, Kasagi F, Shore RE. Solid cancer incidence in atomic bomb survivors exposed in utero or as young children. $J$ Natl Cancer Inst. 2008;100:428-436. https://doi:10.1093/jnci/ djn045.

2. Delongchamp RR, Mabuchi K, Yoshimoto Y, Preston DL. Cancer mortality among atomic bomb survivors exposed in utero or as young children, October 1950 - May 1992. Radiat Res. 1997;147:385-395.

3. Stewart A, Webb J, Giles D, Hewitt D. Malignant disease in childhood and diagnostic irradiation in utero. Lancet. 1956;268:447. https://doi:10.1016/s0140-6736(56)91923-7. tal radioactive releases from nuclear facilities because of the potentially higher radiosensitivity of tissues and organs of the fetus and newborn compared to adults. The Belarusian in utero cohort together with the parallel Ukrainian in utero cohort provides a rare opportunity to learn about the radiation-related risk of thyroid cancer and other health effects of exposure to ionizing radiation during gestation.

\section{Acknowledgement}

This work was supported by the Intra-Agency Agreement between the National Institute of Allergy and Infectious Diseases (NIAID, USA) and the National Cancer Institute (NCI, USA), NIAID agreement \#DCC-OD-12-900, and by the Intramural Research Program of the Division of Cancer Epidemiology and Genetics, National Cancer Institute (NCI, NIH, USA), within the framework of the Belarus-U.S. Study of Thyroid Cancer and Other Diseases Following the Chernobyl Accident (Protocol \#OH95C-NO21) through contracts HHSN261201300002C and HHSN261201800015C between the NCI and the RRCRM\&HE (Gomel, Belarus). The authors are grateful to all the subjects and their mothers who participated in the study.

\section{Disclaimer}

Where authors are identified as personnel of the International Agency for Research on Cancer/ World Health Organization, the authors alone are responsible for the views expressed in this article and they do not necessarily represent the decisions, policy, or views of the International Agency for Research on Cancer/ World Health Organization.

\section{Conflict of Interest statement}

The authors declare that they have no competing financial interests or personal relationships that could have appeared to influence the work reported in this paper.

4. Doll R, Wakeford R. Risk of childhood cancer from fetal irradiation. $\mathrm{Br}$ J Radiol. 1997;70:130-139. https://doi:10.1259/bjr.70.830.9135438.

5. Akleyev A, Deltour I, Krestinina L, Sokolnikov M, Tsareva Y, Tolstykh E, Schuz J. Incidence and mortality of solid cancers in people exposed in utero to ionizing radiation: Pooled analyses of two cohorts from the Southern Urals, Russia. PLoS One. 2006;11(8):e0160372. https://doi:10.1371/journal.pone.0160372.

6. Schuz J, Deltour I, Krestinina LY, Tsareva W, Tolstykh El, Sokolnikov ME, Akleyev AV. In utero exposure to radiation and haematological malignancies: pooled analysis of Southern Urals cohorts. $\mathrm{Br} J$ Cancer. 2017;116:126-133. https://doi:10.1038/bjc.2016.373. 
7. Schonfeld SJ, Tsareva W, Preston DL, Okatenko PV, Gilbert ES, Ron E, Sokolnikov ME, Koshurnikova NA. Cancer mortality following in utero exposure among offspring of female Mayak Worker Cohort members. Radiat Res. 2012;178:160-165. https://doi.org/ 10.1667/ RR2848.1.

8. Hatch M, Brenner A, Bogdanova T, Derevyanko A, Kuptsova N, Likhtarev I, Bouville A, Tereshchenko V, Kovgan L, Shpak V, Ostroumova E, Greenebaum E, Zablotska L, Ron E, Tronko M. A screening study of thyroid cancer and other thyroid diseases among individuals exposed in utero to iodine-131 from Chernobyl fallout. J Clin Endocrinol Metab. 2009;94:899-906. https://doi:10.1210/ jc.2008-2049.

9. Hatch M, Brenner AV, Cahoon EK, Drozdovitch V, Little MP, Bogdanova T, Shpak V, Bolshova E, Zamotayeva G, Terekhova G, Shelkovoy E, Klochkova V, Mabuchi K, Tronko M. Thyroid cancer and benign nodules after in utero exposure to fallout from Chernobyl. J Clin Endocrinol Metab. 2019;104:41-48. https://doi:10.1210/jc.2018-00847.

10. Stezhko VA, Buglova EE, Danilova LI, Drozd VM, Krysenko NA, Lesnikova NR, Minenko VF, Ostapenko VA, Petrenko SV, Polyanskaya ON, Rzheutski VA, Tronko MD, Bobylyova 00, Bogdanova TI, Ephstein OV, Kairo IA, Kostin OV, Likhtarev IA, Markov W, Oliynik VA, Shpak VM, Tereshchenko VP, Zamotayeva GA, Beebe GW, Bouville $A C$, Brill $A B$, Burch JD, Fink DJ, Greenebaum E, Howe GR, Luckyanov NK, Masnyk IJ, McConnell RJ, Robbins J, Thomas TL, Voilleque PG, Zablotska LB; Chornobyl Thyroid Diseases Study Group of Belarus, Ukraine, and the USA, 2004. A cohort study of thyroid cancer and other thyroid diseases following the Chornobyl accident: objectives, design, and methods. Radiat Res. 2004:161:481-492.

11. International Commission on Radiological Protection. Doses to the embryo and fetus from intakes of radionuclides by the mother. ICRP Publication 88. Ann. ICRP. 2001;31(1-3):202-214.

12. Drozdovitch V, Minenko V, Kukhta T, Trofimik S, Grakovitch R, Hatch M, Cahoon E, Veyalkin I, Polyanskaya O, Yauseyenka V, Ostroumova

\section{INFORMATION ABOUT AUTHORS}

Vladimir Drozdovitch, Ph.D., Staff Scientist, Division of Cancer Epidemiology and Genetics, National Cancer Institute, National Institutes of Health, Bethesda, MD, USA. ORCID: 0000-0002-7952-379X

Vasilina V. Yauseyenka, Ph.D., Project Administrator, Republican Research Center for Radiation Medicine and Human Ecology, Gomel, Belarus

Victor F. Minenko, Ph.D., Leading Scientist, Institute for Nuclear Problems, Belarusian State University, Minsk, Belarus

Ilya V. Veyalkin, Ph.D., Chief, Epidemiology Laboratory, Republican Research Center for Radiation Medicine and Human Ecology, Gomel, Belarus. ORCID: 0000-00019935-691X

Tatiana S. Kukhta, M.S., Scientist, The Joint Institute of Informatics Problems of the National Academy of Sciences of Belarus, Minsk, Belarus
E, Mabuchi K, Rozhko A. Thyroid dose estimates for a cohort of Belarusian persons exposed in utero and during early life to Chernobyl fallout. Health Phys. 2020;118:170-184. https://doi:10.1097/ HP.0000000000001135.

13. Drozdovitch V, Kukhta T, Minenko V, Trofimik S, Bouville A, Potischman N. Reliability of questionnaire data in the distant past: relevance for radiation exposure assessment. Health Phys. 2016;110:74-92. https://doi:10.1097/HP.0000000000000406.

14. Landis JR, Koch GG. The measurement of observer agreement for categorical data. Biometrics 1977;33:159-174. https://doi.org/ $10.2307 / 2529310$.

15. Likhtarov I, Kovgan L, Chepurny M, Ivanova O, Boyko Z, Ratia G, Masiuk S, Gerasymenko V, Drozdovitch V, Berkovski V, Hatch M, Brenner A, Luckyanov N, Voilleque P, Bouville A. Estimation of the thyroid doses for Ukrainian children exposed in utero after the Chornobyl accident. Health Phys. 2011;100:583-593. https://doi: 10.1097/ HP.0b013e3181ff391a.

16. Yauseyenka V, Drozdovitch V, Ostroumova E, Polyanskaya O, Minenko V, Brenner A, Hatch M, Little MP, Cahoon EK, Kukhta T, Starastsenka L, Grakovitch R, Cheshik A, Veyalkin I, Rozhko A, Mabuchi $\mathrm{K}$. Belarusian in utero cohort: new opportunity to evaluate health effects of prenatal and early-life exposure to ionizing radiation. J Radiol Prot. 2020;40:280-295. https://doi:10.1088/1361-6498/ ab5c08.

17. Kukhta T, Minenko V, Trofimik S, Drozdovitch V. Reliability of thyroid doses due to ${ }^{131} \mathrm{I}$ intake exceeding $5 \mathrm{~Gy}$ in a cohort of Belarusian children exposed to Chernobyl fallout. Radiat Environ Biophys. 2021;60:179-191. https://doi:10.1007/s00411-020-00882-7.

18. Bunin GR, Gyllstrom ME, Brown JE, Kahn EB, Kushi LH. Recall of diet during a past pregnancy. Am J Epidemiol. 2001;154:11361142. https://doi:10.1093/aje/154.12.1136.

Rimma I. Grakovitch, M.S., Dosimetrist, Republican Research Center for Radiation Medicine and Human Ecology, Gomel, Belarus

Sergey Trofimik, M.S., Leading Programmer, Institute for Nuclear Problems, Belarusian State University, Minsk, Belarus

Olga N. Polyanskaya, M.D., Head of DCC, Republican Research Center for Radiation Medicine and Human Ecology, Gomel, Belarus (deceased)

Liliya Starastsenka, M.S., Engineer-Programmer, Republican Research Center for Radiation Medicine and Human Ecology, Gomel, Belarus

Elizabeth K. Cahoon, Ph.D., Earl Stadtman Investigator, Division of Cancer Epidemiology and Genetics, National Cancer Institute, National Institutes of Health, Bethesda, MD, USA. ORCID: 0000-0002-8028-0588

Maureen Hatch, Ph.D., Staff Scientist, Division of Cancer Epidemiology and Genetics, National Cancer Institute, 


\section{ЕПІДЕМІОЛОГІЯ}

ТА Д0ЗИМЕТРІЯ

National Institutes of Health, Bethesda, MD, USA (retired). ORCID: 0000-0001-9209-1269

Mark P. Little, Ph.D., Senior Investigator, Division of Cancer Epidemiology and Genetics, National Cancer Institute, National Institutes of Health, Bethesda, MD, USA. ORCID: 0000-0003-0980-7567

Alina V. Brenner, M.D., Ph.D., Senior Scientist, Department of Epidemiology, Radiation Effects Research Foundation, Hiroshima, Japan. ORCID: 0000-0002-8556-3907 Evgenia Ostroumova, M.D., Ph.D., Scientist, Environment and Lifestyle Epidemiology Branch, International
Agency for Research on Cancer, World Health Organization, Lyon, France. ORCID: 0000-0003-4729-1733

Kiyohiko Mabuchi, M.D., Dr.PH., Senior Scientist, Division of Cancer Epidemiology and Genetics, National Cancer Institute, National Institutes of Health, Bethesda, MD, USA. ORCID: 0000-0002-8867-8777

Alexander V. Rozhko, M.D., D.Sc., Director, Republican Research Center for Radiation Medicine and Human Ecology, Gomel, Belarus 